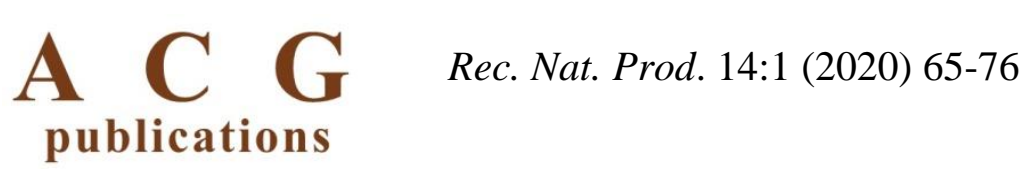

records of natural products

\title{
Comparative Effects of Flavonoids from Fructus Sophorae on Rat Osteoblasts in vitro
}

\author{
Yong Yang ${ }^{1 \dagger}$, Yaping Tian $\odot 2 \dagger$, Qinghe Zhang ${ }^{3}$, Xiaoqing $\mathbf{L i} \odot 1$, \\ Yun Fu $\odot^{1}$, Haotian Pei ${ }^{1}$ and Dan Lui ${ }^{1 *}$
${ }^{1}$ School of Pharmaceutical Sciences, Jilin University, Fujin Road 1266, Changchun, Jilin 130021, China
${ }^{2}$ Department of Dermatology and Venerology, $1^{\text {st }}$ Hospital of Jilin University, Changchun, Jilin 130021, China Jilin 130000, China \\ ${ }^{3}$ College of Pharmacy, Changchun University of Chinese Medicine, Boshuo Road 1035, Changchun,
}

(Received April 27, 2019; Revised June 12, 2019; Accepted June 14, 2019)

\begin{abstract}
Fructus Sophorae (FS), the dry mature fruit of Sophora japonica Leguminosae, is a valuable traditional Chinese medicine resource with flavonoids as the major active ingredients. To identify the plant-derived estrogenlike flavonoids serving as potential osteoporosis chemopreventive agents, we isolated and identified 27 flavonoids compounds, including 17 compounds obtained for the first time from FS. To screen out the flavonoids with estrogen-like biological behavior from the 11 high yield compounds, we set up an in vitro screening system in rat osteoblast MC3T3-E1 cells including MTT assay, alkaline phosphatase staining and Alizarin red S staining assay to examine the effects on cell proliferation, differentiation and mineralization of osteoblast cells respectively. Six flavonoids, including genistein, sophoricoside, sophorabioside, sophoraflavonoloside, nicotiflorin and rutin, significantly increased the cellular activity of MC3T3-E1 cells. Furthermore, blocking the estrogen receptor signaling by tamoxifen compromised the effects above significantly, suggesting the 6 compounds behave as estrogen-like reagents. Moreover, the interaction between the six flavonoids from FS and estrogen receptor was clarified by molecular docking method from Glide XP. Collectively, being used as food and medicine in China, FS is rich in flavonoids with estrogen-like effects, may be used as healthy supplementary in treating postmenopausal women osteoporosis.
\end{abstract}

Keywords: Fructus Sophorae; flavonoid; phytoestrogens; estrogen receptor; osteoporosis. ㄷ 2019 ACG Publications. All rights reserved.

\section{Introduction}

Osteoporosis is a bone disease featured with reduced quality of bone mass and microarchitecture, leading to increasing risk of fragility or bone fracture which would cause considerable

\footnotetext{
* Correspondence: ludan@jlu.edu.cn ; Tel.: +86-431-8561-9299; Fax.: 86-431-8561-9299;

$\uparrow$ These authors contribute equally. 
morbidity and mortality [1,2]. Deficiency of ovarian estrogen production is a major reason for osteoporosis in over 200 million postmenopausal women worldwide [3, 4]. Currently hormone replacement is the most effective therapy to ameliorate postmenopausal symptoms and lower or prevent osteoporosis, however the increased carcinogenic risk of hormones and synthetic hormone-like drugs $[5,6]$ stimulates the demand of seeking for safe and health natural products for replacement, mostly phytoestrogens and novel estrogen-like compounds from plants [7]. Phytoestrogens (isoflavones, flavonoids, coumestanes, lignans, stilbenes and so on) are polyphenol compounds rich in several edible or medicinal plants (soybeans, flaxseeds and so on), mostly belonging to the Leguminosae family $[7,8]$. Owing to the structural and functional similarity with steroid hormone, phytoestrogens isolated from plants or herbs are verified to be potential hormone replacement reagent via cell line or ovarectomized rodent animal model [7]. Clinically, to avoid exposure to exogenous hormones and toxic drugs, large populations of postmenopausal women are shifting to phytoestrogens for relief $[7,10,11]$. However, more scientific evidences in the study on the protective properties of phytoestrogens on osteoporosis are required for broader clinical application.

Fructus Sophorae (FS) or Huaijiao, the dry mature fruit of Sophora japonica Leguminosae, is a well-established traditional Chinese medicine listed in the Chinese Pharmacopoeia, which has been used as a heat-clearing and fire-purging, cooling blood and hemostatic agent in China. Extracts from Sophora japonica were proved to prevent bone loss in ovariectomized rat's model [12]. Constituents studies of FS showed that it is a natural excellent source for flavonoids which account $20.2 \%$ of the total weight $[13,14]$. FS flavonoids mainly belong to isoflavonoid and flavonols along with their glycosides, serving as the therapeutic components of FS [15,16]. Further, genistein [17] and sophoricoside [18] isolated from FS show osteoporosis chemopreventive properties. Sophoricoside, genistin, genistein, rutin, quercetin and kaempferol are the known major compounds of FS, occupying $11.4 \%$ of the total weight $[13,14]$. In our present study, we focused on isolating and identifying the unknown flavonoids in FS, and investigated their osteogenesis effects. Osteogenic effects of the compounds were tested in cultured osteoblasts MC3T3-E1 cells by alkaline phosphatase (ALP) staining. Alizarin red S (ARS) staining was used to evaluate the cellular mineralization. Tests of co-treatment with tamoxifen and molecular docking of estrogen receptor (ER) $\beta$ protein were carried to verify if the flavonoids interacted with ER [19,20].

\section{Materials and Methods}

\subsection{Materials}

FS were purchased from Hebei, China, in November 2014 and authenticated by Professor Guangshu Wang in the department of Pharmacognosy, Jilin University, China. A voucher specimen (No. FSJ-20141012) was prepared and kept in the Jilin University.

MC3T3-E1 cells were gifts from Professor Hui Xu's lab (Jilin University). Reagents for cell culture, including alpha-Minimum Essential Medium ( $\alpha$-MEM), Fetal bovine serum (FBS), and penicillin/ streptomycin were all purchased from Gibco. 3-(4,5-Dimethyl-2-thiazolyl)-2,5-iphenyl-2-H-tetrazolium bromide (MTT), 17 $\beta$-estradiol and tamoxifen were obtained from Sigma. Silica gel (Tsingtao Ocean Chemical Co., Ltd, Shandong, China), Sephadex LH-20 (GE Healthcare Bio-Science AB, Sweden), and ODS (Silicycle, Quebec City, Canada) were used in column chromatography. All other analytical grade reagents were purchased from Beijing Chemical Factory (Beijing, China).

\subsection{Extraction and Isolation}

FS, the dried fruits of Sophora japonica L. (5.0 kg) were pulverized (120 mesh) and then extracted for $3 \mathrm{~h}$ with $70 \% \mathrm{EtOH}$ ( $40 \mathrm{~L}, 3$ times) at $50-60^{\circ} \mathrm{C}$. The extract solution was removed to afford the EtOH extract, which was then suspended in distilled $\mathrm{H}_{2} \mathrm{O}$ and successively partitioned with $n$-Hexane, EtOAc and $n-\mathrm{BuOH}$. The EtOAc soluble fraction $(159.0 \mathrm{~g})$ and $n-\mathrm{BuOH}$ soluble fraction $(1320.0 \mathrm{~g})$ were obtained respectively. 
The $n$-BuOH-soluble fraction (300.0 g) was subjected to silica gel column chromatography, gradiently eluted with $\mathrm{CH}_{2} \mathrm{Cl}_{2}-\mathrm{MeOH}$ by stepwise addition of $\mathrm{MeOH}(20: 1-0: 1 \mathrm{v} / \mathrm{v})$ to yield 6 fractions. Fraction $1(4.0 \mathrm{~g})$ was subjected to silica gel $\left(\mathrm{CH}_{2} \mathrm{Cl}_{2}-\mathrm{MeOH} 22: 1\right)$ to obtain compound $14(40 \mathrm{mg})$. Fraction $2(80.2 \mathrm{~g})$ was subjected to silica gel $\left(\mathrm{CH}_{2} \mathrm{Cl}_{2}-\mathrm{MeOH}\right.$ 15:1) and $\mathrm{ODS}\left(\mathrm{MeOH}-\mathrm{H}_{2} \mathrm{O}\right.$ 25:75-100:0) column chromatography to obtain compounds 3 (39.0 g), 17 (5.8 g). Fraction 3 (68 g) was subjected to ODS ( $\mathrm{MeOH}-\mathrm{H}_{2} \mathrm{O}$ 20:80-100:0) column chromatography and recrystallization $\left(\mathrm{MeOH}-\mathrm{H}_{2} \mathrm{O}\right)$ to obtain compounds $4(31.1 \mathrm{~g}), \mathbf{1 6}(3.0 \mathrm{~g})$. Fraction $4(45.5 \mathrm{~g})$ was subjected to silica gel $\left(\mathrm{CH}_{2} \mathrm{Cl}_{2}-\mathrm{MeOH} 8: 1\right)$ to obtain compound $21(2.0 \mathrm{~g})$. Fraction $6(11.0 \mathrm{~g})$ was subjected to Sephadex LH-20 $(\mathrm{MeOH})$ chromatography to obtain compound $22(35.0 \mathrm{mg})$.

The EtOAc-soluble fraction (159.0 g) was subjected to silica gel column chromatography, gradiently eluted with $\mathrm{CH}_{2} \mathrm{Cl}_{2}-\mathrm{MeOH}$ by stepwise addition of $\mathrm{MeOH}(30: 1-0: 1$, v/v) to yield 7 fractions. Fraction $2(12.0 \mathrm{~g})$ was subjected to silica gel (PE-EtOAc-acetone- $\mathrm{H}_{2} \mathrm{O}, 10: 4: 1: 1$, upper phase), Sephadex LH-20 (MeOH) chromatography and HPLC (RP-18, MeOH- $\mathrm{H}_{2} \mathrm{O}$ 60:40) chromatography to obtain compounds $\mathbf{1}(0.7 \mathrm{~g}), \mathbf{5}(9 \mathrm{mg}), \mathbf{8}(12 \mathrm{mg}), \mathbf{9}(58 \mathrm{mg}), \mathbf{1 0}(5 \mathrm{mg}), \mathbf{1 1}(3 \mathrm{mg}), \mathbf{1 2}(26 \mathrm{mg})$, and 26 (11 mg). Fraction 3 (31.6 g) was subjected to silica gel (EtOAc-Acetone, 40:1-1:1), Sephadex LH-20 $(\mathrm{MeOH})$ chromatography, HPLC (RP-18, $\mathrm{MeOH}-\mathrm{H}_{2} \mathrm{O}$ 58:42) chromatography and crystallization $\left(\mathrm{MeOH}-\mathrm{H}_{2} \mathrm{O}\right)$ to obtain compounds $6(103.2 \mathrm{mg}), \mathbf{1 3}(0.5 \mathrm{~g}), \mathbf{1 8}(8 \mathrm{mg}), 25(0.3 \mathrm{~g})$ and $27(0.2 \mathrm{~g})$. Fraction $4(28.0 \mathrm{~g})$ was subjected to silica gel $\left(\mathrm{CH}_{2} \mathrm{Cl}_{2}-\mathrm{MeOH} 10: 1\right)$ to obtain compound 15 (3.8 g). Fraction $5(16 \mathrm{~g})$ was subjected to Sephadex LH-20 $(\mathrm{MeOH})$ chromatography to obtain compounds 7 $(11.0 \mathrm{mg}), \mathbf{1 9}(6.5 \mathrm{mg}), \mathbf{2 3}(6.5 \mathrm{mg})$ and $\mathbf{2 4}(5.9 \mathrm{mg})$. Fraction $6(14.3 \mathrm{~g})$ was subjected to Sephadex LH$20(\mathrm{MeOH})$ chromatography and HPLC (RP-18, MeOH- $\left.\mathrm{H}_{2} \mathrm{O} 55: 45\right)$ to obtain compounds $2(2.1 \mathrm{~g})$ and 20 (37 mg).

\subsection{Preparation of Test Samples}

Compounds $1,2,3,4,13,15,16,17,21,25$ and 27 were dissolved into $0.1 \mathrm{M}$ stock solution by DMSO respectively, and further diluted by culture medium in different concentrations before use $(0.1 \mathrm{mM}, 1.0 \mu \mathrm{M}, 0.01 \mu \mathrm{M}) .17 \beta$-estradiol, the positive control and tamoxifen, the estrogen-receptor inhibitor, are both solved into the final concentration of $5.0 \mu \mathrm{M}$. The final concentration of DMSO was controlled within $0.1 \%(\mathrm{v} / \mathrm{v})$.

\subsection{Cell Culture}

MC3T3-E1 cells were maintained at $37{ }^{\circ} \mathrm{C}$ with $5 \% \mathrm{CO}_{2}$ in $\alpha$-MEM $(10 \%$ FBS and $1 \%$ penicillin/streptomycin). To induce differentiation, $50 \mathrm{mg} / \mathrm{L} L$-ascorbic acid and $10 \mathrm{mmol} / \mathrm{L} \beta$ glycerophosphate were supplemented in the culture medium.

\subsection{MTT Proliferation Assay}

The cell viability of MC3T3-E1 cells treated by the test compounds was determined by MTT assay. Briefly, MC3T3-E1 cells were seeded in 96-well culture plates at a density of $5 \times 10^{3}$ cells/well. After culture for $24 \mathrm{~h}$, the cells were treated with varying concentrations of test compounds for another 2 days. $20 \mu \mathrm{l}$ MTT solution $(5 \mathrm{mg} / \mathrm{mL}$ ) were added into each well and incubated for $4 \mathrm{~h}$ to allow the formation of purple formazan crystal. For the co-treatment with the estrogen-receptor inhibitor, tamoxifen was added $4 \mathrm{~h}$ before the drugs administration. Discarded the supernatant and dissolved the formazan crystals with $150 \mu \mathrm{l}$ DMSO followed by $10 \mathrm{~min}$ incubation in a shaker. Measure the absorbance by Model 50 (Bio-Rad, USA) at $490 \mathrm{~nm}$.

\subsection{Alkaline Phosphatase Staining}

MC3T3-E1 cells were seeded in 24-well plates at a density of $2 \times 10^{4}$ cells/well in differentiation medium. In the negative control, the estrogen-receptor inhibitor (tamoxifen) was added $4 \mathrm{~h}$ before the drugs pretreated the MC3T3-E1 cells. After 14 days, ALP staining was measured via modified calcium- 
cobalt (Ca-Co) method [21]. After 10 min fixation by $90 \%$ alcohol and $4 \mathrm{~h}$ incubation at $37^{\circ} \mathrm{C}$, the cells were stained by $2 \%$ cobalt nitrate and $1 \%$ ammonium sulfide in turn [21]. Wash the cells and took photographs under the microscope. The ALP-positive cells exhibit dark-brown color in the bright field.

\subsection{Mineralization Assay}

Alizarin red S (ARS) staining was a method for the measure of mineralization [22]. Seeded the MC3T3-E1 cells in 24-well at a density of $2 \times 10^{4}$ cells/well in differentiation medium for 21 days. After washing with PBS twice, fixed the specimens with $95 \%$ ethanol at room temperature for $10 \mathrm{~min}$. Rinsed the plate with distilled $\mathrm{H}_{2} \mathrm{O}$, and stained the cells with $0.1 \%$ alizarin red $\mathrm{S}$ solution $(\mathrm{pH} 8.3$ ) for 30 min at $37{ }^{\circ} \mathrm{C}$. Rinsed the cells with distilled $\mathrm{H}_{2} \mathrm{O}$ and took photographs under the microscope. Cells with pink color are the positive ARS staining suggesting the formation of bone nodule.

\subsection{Molecular Docking within Estrogen Receptor}

Molecular docking studies of anti-osteoporosis bioactive compounds were conducted using Schrödinger Maestro (2015-2, Schrödinger, USA). The structure imformation of Human ER $\beta$ binding with genistein was downloaded from PDB websites (1QKM, www.rcsb.org/pdb/) [23]. Optimized the structure of $E R \beta$ using GLIDE software (v.6.7, Schrödinger, USA) with the default constraint set of 0.30 $\AA$ RSD [24]. The receptor grid box was restricted to the size of $2 \mathrm{~nm}$ at the active site [25]. The graphs of docking results were plotted with PyMol (Schrödinger, USA).

\subsection{Statistical Analysis}

All of the experiments were performed at least for three independent times. The values in Figure 2 and 5 were presented as means \pm standard deviation (SD). One-way ANOVA analysis and graph plotting was perform via GraphPad Prism 5 software package (GraphPad Inc., San Diego, USA). $P$-value under 0.05 was considered to be statistically significant.

\section{Results and Discussion}

\subsection{Extraction and Isolation}

The $70 \%$ EtOH extract of FS was partitioned with $n$-Hexane, EtOAc and $n$-BuOH. The EtOAc and $n-\mathrm{BuOH}$ soluble fractions were separated and purified on silica gel, ODS, Sephadex LH-20 columns and semi-preparative HPLC to produce 27 compounds. The structures of compounds 1-27, shown in Figure 1, were identified by physicochemical properties, NMR spectral analyses and comparison with known samples as isoflavones, genistein (1), genistin (2), sophoricoside (3), sophorabioside (4), biochanin A (5), sissotrin (6), oroboside (7), pratensein (8), prunetin (9), 3'-methylorobol (10), dehydroferreirin (11), cajanin (12), tectoridin (13), ononin (14); flavonols, kaempferol (15), sophoraflavonoloside (16), nicotiflorin (17), $\alpha$-rhamnoisorobin (18), populnin (19), astragalin (20), rutin (21), quercetin-3-O- $\beta$-D-sophoroside (22), quercitrin (23), isoquercitrin (24); flavone, thevetiaflavone (25), genkwanin (26) and dihydroflavone, choerospondin (27).

Among them seventeen compounds 5-12, 13, 17, 19, and 22-27 were first reported from FS, and six compounds 10, 11, 19, 22, 25, 26 and 27 were obtained from genus Sophora Linn. for the first time(https://scifinder.cas.org). Details about the structure analysis of the chemicals would be described in supplemental data 1. 


\begin{tabular}{|c|c|c|c|c|c|c|c|}
\hline $\begin{array}{c}\text { Compound } \\
\text { No }\end{array}$ & Name & $\mathbf{R}_{1}$ & $\mathbf{R}_{2}$ & $\mathbf{R}_{\mathbf{3}}$ & $\mathbf{R}_{4}$ & $\mathbf{R}_{5}$ & $\mathbf{R}_{6}$ \\
\hline $\mathbf{1}$ & Genistein & $-\mathrm{OH}$ & $-\mathrm{H}$ & $-\mathrm{OH}$ & $-\mathrm{H}$ & $-\mathrm{H}$ & $-\mathrm{OH}$ \\
\hline 2 & Genistin & $-\mathrm{OH}$ & $-\mathrm{H}$ & -OGlc & $-\mathrm{H}$ & $-\mathrm{H}$ & $-\mathrm{OH}$ \\
\hline 3 & Sophoricoside & $-\mathrm{OH}$ & $-\mathrm{H}$ & $-\mathrm{OH}$ & $-\mathrm{H}$ & $-\mathrm{H}$ & -OGlc \\
\hline 4 & Sophorabioside & $-\mathrm{OH}$ & $-\mathrm{H}$ & $-\mathrm{OH}$ & $-\mathrm{H}$ & $-\mathrm{H}$ & -OGlc- $(2 \rightarrow 1)-$ Rha \\
\hline 5 & Biochanin A & $-\mathrm{OH}$ & $-\mathrm{H}$ & $-\mathrm{OH}$ & $-\mathrm{H}$ & $-\mathrm{H}$ & $-\mathrm{OCH}_{3}$ \\
\hline 6 & Sissotrin & $-\mathrm{OH}$ & $-\mathrm{H}$ & -OGlc & $-\mathrm{H}$ & $-\mathrm{H}$ & $-\mathrm{OCH}_{3}$ \\
\hline 7 & Oroboside & $-\mathrm{OH}$ & $-\mathrm{H}$ & -OGlc & $-\mathrm{H}$ & $-\mathrm{OH}$ & $-\mathrm{OH}$ \\
\hline 8 & Pratensein & $-\mathrm{OH}$ & $-\mathrm{H}$ & $-\mathrm{OH}$ & $-\mathrm{H}$ & $-\mathrm{OH}$ & $-\mathrm{OCH}_{3}$ \\
\hline 9 & Prunetin & $-\mathrm{OH}$ & $-\mathrm{H}$ & $-\mathrm{OCH}_{3}$ & $-\mathrm{H}$ & $-\mathrm{OH}$ & $-\mathrm{OCH}_{3}$ \\
\hline 10 & 3'-Methylorobol & $-\mathrm{OH}$ & $-\mathrm{H}$ & $-\mathrm{OH}$ & $-\mathrm{H}$ & $-\mathrm{OCH}_{3}$ & $-\mathrm{OH}$ \\
\hline 11 & Dehydroferreirin & $-\mathrm{OH}$ & $-\mathrm{H}$ & $-\mathrm{OH}$ & $-\mathrm{OH}$ & $-\mathrm{H}$ & $-\mathrm{OCH}_{3}$ \\
\hline 12 & Cajanin & $-\mathrm{OH}$ & $-\mathrm{H}$ & $-\mathrm{OCH}_{3}$ & $-\mathrm{OH}$ & $-\mathrm{H}$ & $-\mathrm{OH}$ \\
\hline 13 & Tectoridin & $-\mathrm{OH}$ & $-\mathrm{OCH}_{3}$ & -OGlc & $-\mathrm{H}$ & $-\mathrm{H}$ & $-\mathrm{OH}$ \\
\hline 14 & Ononin & $-\mathrm{H}$ & $-\mathrm{H}$ & -OGlc & $-\mathrm{H}$ & $-\mathrm{H}$ & -OGlc \\
\hline
\end{tabular}<smiles>[R3]c1cc([R1])c2c(=O)c([R])c(-c3ccc(O)c([R3])c3)oc2c1</smiles><smiles>COc1ccc([C@H]2CC(=O)c3c(O)cc(O)cc3O2)cc1</smiles>

27 Choerospondin

\begin{tabular}{|c|c|c|c|c|c|}
\hline $\begin{array}{c}\text { Compound } \\
\text { No }\end{array}$ & Name & $\mathbf{R}_{1}$ & $\mathbf{R}_{2}$ & $\mathbf{R}_{3}$ & $\mathbf{R}_{4}$ \\
\hline 15 & Kaempferol & $-\mathrm{OH}$ & $-\mathrm{OH}$ & $-\mathrm{OH}$ & $-\mathrm{H}$ \\
\hline 16 & Sophoraflavonoloside & -OGlc- $(2 \rightarrow 1)-$ Rha & $-\mathrm{OH}$ & $-\mathrm{OH}$ & $-\mathrm{H}$ \\
\hline 17 & Nicotiflorin & -OGlc-(6 $\rightarrow 1)-$ Rha & $-\mathrm{OH}$ & $-\mathrm{OH}$ & $-\mathrm{H}$ \\
\hline 18 & $\alpha$-Rhamnoisorobin & $-\mathrm{OH}$ & $-\mathrm{OH}$ & -ORha & $-\mathrm{H}$ \\
\hline 19 & Populnin & $-\mathrm{OH}$ & $-\mathrm{OH}$ & -OGlc & $-\mathrm{H}$ \\
\hline 20 & Astragalin & -OGlc & $-\mathrm{OH}$ & $-\mathrm{OH}$ & $-\mathrm{H}$ \\
\hline 21 & Rutin & -OGlc-(6 $\rightarrow 1)-$ Rha & $-\mathrm{OH}$ & $-\mathrm{OH}$ & $-\mathrm{OH}$ \\
\hline 22 & $\begin{array}{l}\text { Quercetin-3-O- } \beta \text {-D- } \\
\text { sophoroside }\end{array}$ & -OGlc- $(2 \rightarrow 1)-$ Rha & $-\mathrm{OH}$ & $-\mathrm{OH}$ & $-\mathrm{OH}$ \\
\hline 23 & Quercitrin & $-\mathrm{OH}$ & $-\mathrm{OH}$ & -ORha & $-\mathrm{OH}$ \\
\hline 24 & Isoquercitrin & $-\mathrm{OH}$ & $-\mathrm{OH}$ & -OGlc & $-\mathrm{OH}$ \\
\hline 25 & Thevetiaflavone & $-\mathrm{H}$ & $-\mathrm{OCH}_{3}$ & $-\mathrm{OH}$ & $-\mathrm{H}$ \\
\hline 26 & Genkwanin & $-\mathrm{H}$ & $-\mathrm{OH}$ & $-\mathrm{OCH}_{3}$ & $-\mathrm{H}$ \\
\hline
\end{tabular}

Figure 1. Structures of the $\mathbf{2 7}$ compounds isolated from FS in this study. Including $\mathbf{1 4}$ isoflavones (1-14), 10 flavonols (15-24), 2 flavones ( 25 and 26) and 1 dihydroflavone (27). 


\subsection{Primary Screening of High Yield Compounds on the Proliferation of MC3T3-E1 Cells by MTT}

As shown in Figure 2 (A-B), each compound from 11 high yield flavonoids (compounds 1, 2, 3, 4, $13,15,16,17,21,25$ and 27) was diluted into 3 concentrations, $0.01 \mu \mathrm{M}, 1.0 \mu \mathrm{M}$ and $100 \mu \mathrm{M}$. For each compound, there are also a blank group as negative control and $17 \beta$-estradiol $(5.0 \mu \mathrm{M})$ as positive control. After cell culture for $48 \mathrm{~h}$, we performed MTT assay to examine the effects of the compounds on the proliferation of MC3T3-E1 cells. Compounds $\mathbf{1}, \mathbf{3}$ and $\mathbf{1 5}$ promoted proliferation of MC3T3-E1 cells at the concentration of 0.01 and $1.0 \mu \mathrm{M}$, but 3 and $\mathbf{1 5}$ showed no significant effects at $100 \mu \mathrm{M}$, and 1 even inhibited proliferation at $100 \mu \mathrm{M}$.
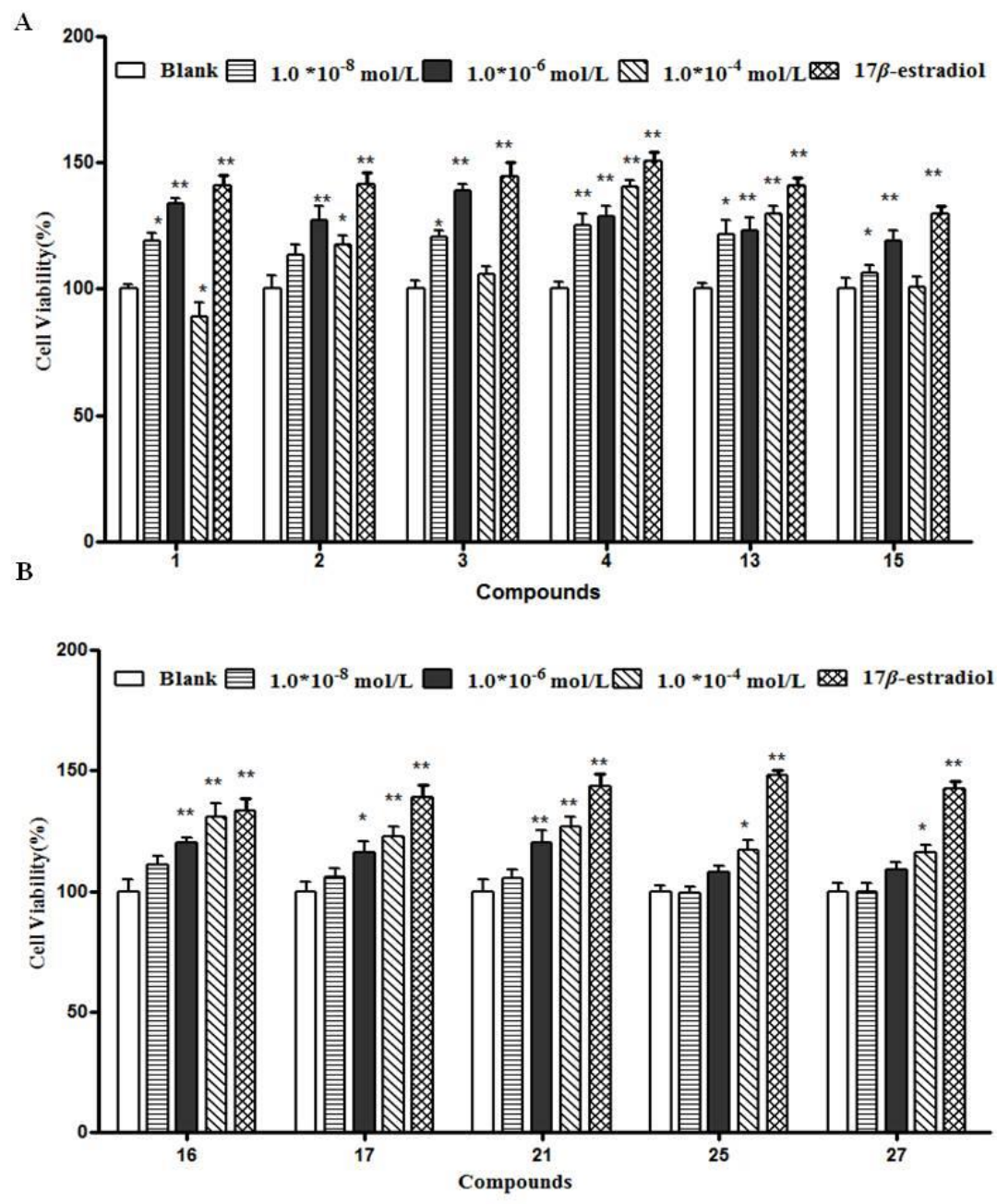

Figure 2. Primary screening of 11 high yield compounds on the proliferation of MC3T3-E1 cells by MTT assay. (A) Effects of 1, 2, 3, 4, 13 and 15 on osteoblast proliferation of MC3T3-E1 cells. (B) Effects of 16, 17, 21, 25 and 27 on osteoblast proliferation of MC3T3-E1 cells. For each compound, there are one negative control (blank group), one positive control $(5.0 \mu \mathrm{M} 17 \beta$-estradiol), and 3 different concentrations of each chemical $(0.01 \mu \mathrm{M}, 1.0 \mu \mathrm{M}$ and $100 \mu \mathrm{M})$. MTT assay of each compound has been analyzed by cell viability $(\%)$, which is calculated using following formula. Cell viability $(\%)=\left(\mathrm{OD}_{490}\right.$ of test compound wells $/ \mathrm{OD}_{490}$ of control wells) $\times 100 \%$. Each assay was repeated for three times independently. $(* p<0.05, * * p<0.01$.$) .$

Other compounds showed a dose-dependent effect on the MC3T3-E1 cells proliferation. Among them, cells treated with compounds $\mathbf{4}$ and $\mathbf{1 3}$ have a significant promoting effect at the concentration of $0.01 \mu \mathrm{M}$, while compounds $\mathbf{2 5}$ and $\mathbf{2 7}$ treatment have this effect only at the high concentration $(100 \mu \mathrm{M})$ comparing to the control group. At the concentration of $1.0 \mu \mathrm{M}$, compounds $\mathbf{1 , 2 , 3}$ and $\mathbf{1 5}$ exhibit the maximal cell viability of $133.8 \%, 127.2 \%, 138.7 \%$ and $118.8 \%$ respectively $(p<0.01$ for all $)$. While at the concentration of $100.0 \mu \mathrm{M}$, compounds $4,13,16,17,21,25$ and 27 reach the maximal cell viability 
of $140.4 \%, 129.6 \%, 131.1 \%, 122.6 \%, 126.8 \%, 117.0 \%$ and $116.0 \%$ respectively $(p<0.05$ for $\mathbf{2 5}$ and $\mathbf{2 7}$, and $p<0.01$ for the rest). For the following experiments, the concentration of each chemical is set as $1.0 \mu \mathrm{M}$ ( 9 compounds excepting 25 and 27$)$ or $100 \mu \mathrm{M}$ ( 25 and 27 ) according to the MTT assay results.

Results of genistein (1) and sophoricoside (3) are consistent with the previous work in FS [17, 18]. Other 4 compounds were first reported as the chemoprotective osteoporosis compounds in osteoblast cells (rat MC3T3-E1 cells), especially nicotiflorin (compound 17) were obtained from FS for the first time. The test of proliferative activity on MC3T3-E1 cells showed that 11 compounds promoted cells proliferation in different degrees. But the structure-activity relationship is not distinct due to the insufficient of sample quantity.
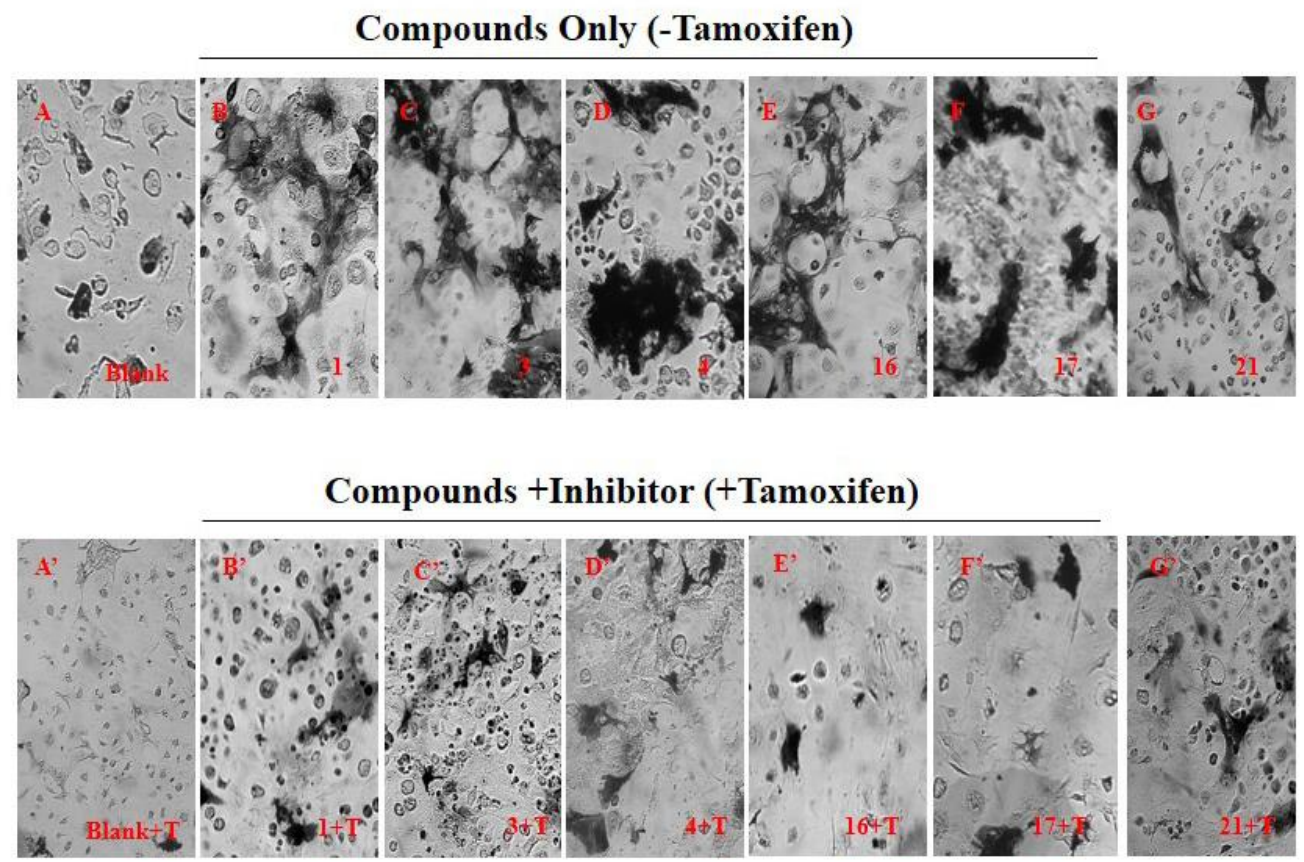

Figure 3. Effects of 11 compounds with or without tamoxifen on ALP staining in MC3T3-E1cells. Group A is the blank group as negative control. The concentration of each chemical is set as $1.0 \mu \mathrm{M}$ ( 9 compounds excepting 25 and 27) or $100 \mu \mathrm{M}$ (compound 25 and 27) according to the MTT assay results of Figure 2. After ALP staining, 6 compounds from the 11 high yield compounds have obvious stronger signal than blank group, including 1(B), 3(C), 4(D), 16(E), 17(F) and 21(G). Other 5 groups have similar intensity signal with blank groups are not shown in Figure 3. From A' to G' groups, the inhibitor of ER signaling, tamoxifen (shorten as $+\mathrm{T}$ ), was added in each group with a final concentration of $5.0 \mu \mathrm{M}$ comparing to A to G groups respectively. ALP signaling was significantly reduced to the blank level after tamoxifen administration as shown in group B' to group G'. Arrows stand for the representative ALP staining positive cells. Each assay was repeated for three times independently.

\subsection{Effect of Compounds on the Differentiation of MC3T3-E1 Cells}

ALP enzyme participated in the regulation of calcium deposition and was generally used as a key marker in early differentiation process of osteoblast $[26,27]$. To investigate effects of compounds on the differentiation of MC3T3-E1 cells, we have performed ALP staining. As shown in Figure 3, treatment with compounds $1,3,4,16,17$ and 21 at concentrations of $1.0 \mu \mathrm{M}$ showed significant ALP positive staining with several black granules deposition in MC3T3-E1 cells comparing with blank control (Figure 3 A-G). The other compounds fail to have the obvious difference ALP positive signal comparing to the blank group. The results suggested that these six compounds (compounds 1, 3, 4, 16, 17 and 21) could enhance ALP activity in MC3T3-E1 cells groups. 


\subsection{Effect of Compounds on the Mineralization of MC3T3-E1 Cells}

In the process of osteoblast differentiation, a large number of calcium ions could deposit and form mineralized nodules, which could be stained by alizarin red S (ARS) with pink or pale purple color. We examined the mineralization effects of 6 ALP positive chemicals (compounds $1,3,4,16,17$ and 21 ) of MC3T3-E1 cells through ARS staining. Highly consistent with the ALP staining results above, compounds $1,3,4,16,17$, and 21 exhibited increased ARS positive area at concentrations of $1.0 \mu \mathrm{M}$ comparing to the control group. As shown in Figure 4, the pink positive staining cells treated with compounds $1,3,4,16$, and 21 were significantly increased, and the mineralized nodules were obviously formed compared with control. These results indicated that these five compounds could enhance mineralization of MC3T3-E1 cells. The positive staining cells were increased and clustered treated with $\mathbf{1 7}$, but no obvious mineralized nodules were formed, indicating that the mineralization of $\mathbf{1 7}$ was weak.
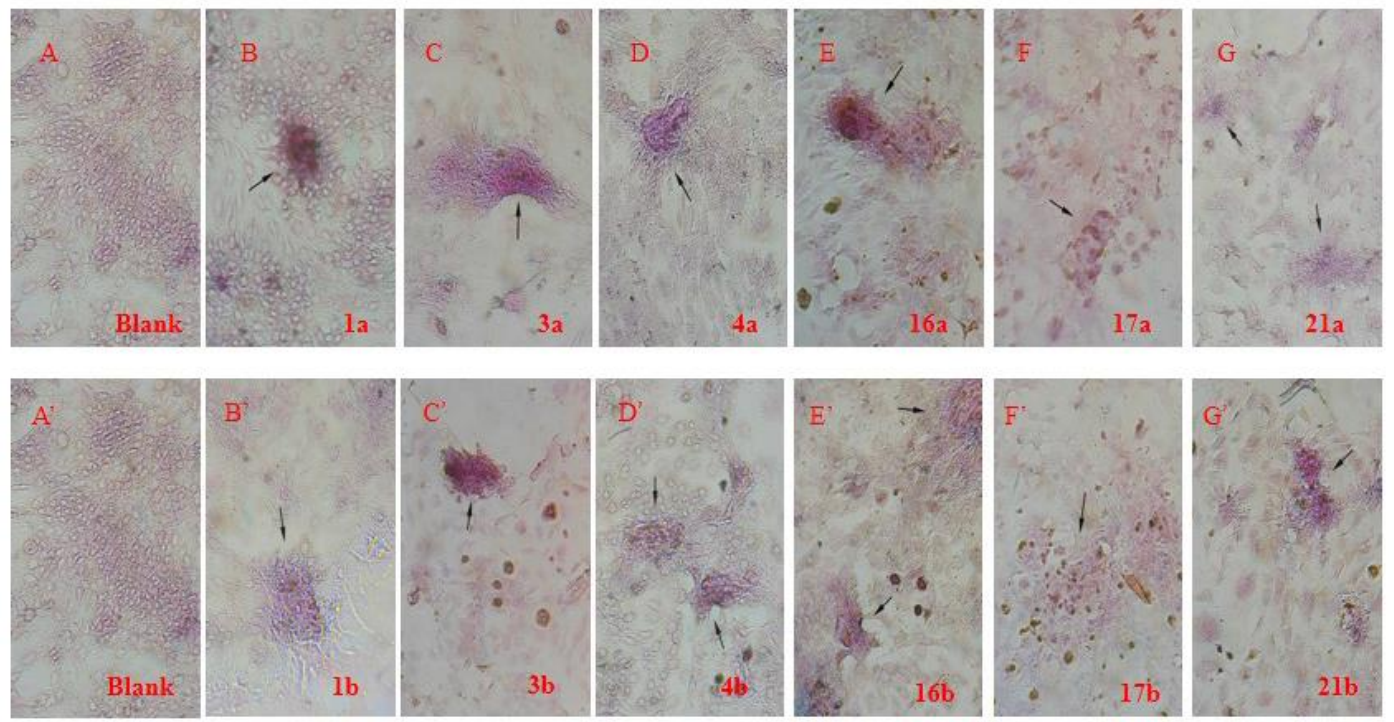

Figure 4. Effects of compounds on Alizarin red S staining in MC3T3-E1cells. Only 6 chemicals with ALP positive signaling (Compounds 1, 3, 4, 16, 17 and 21) were tested by Alizarin red S staining. Arrows indicated the Alizarin red S staining positive cells. Each assay was repeated for three times independently. a: Concentration $1.0 \mu \mathrm{M}(\mathrm{B}-\mathrm{G})$; b: Concentration $100 \mu \mathrm{M}\left(\mathrm{B}^{\prime}-\mathrm{G}^{\prime}\right)$.

Positive results in ALP staining and calcification tests confirmed the cultured cells have the typical characteristics of mature osteoblast. In this study, 11 compounds with the capable of promoting osteoblast proliferation, among them, 6 compounds $(\mathbf{1}, \mathbf{3}, \mathbf{4}, \mathbf{1 6}, \mathbf{1 7}$ and 21) could enhance ALP activity and promoting calcium salt deposition of osteoblast compared with control, suggesting that the compounds could improve the osteogenic properties of osteoblast, enhancing bone density.

\subsection{Compounds Promote Proliferation and Differentiation of MC3T3-E1 Cells via Estrogen Receptor Pathway}

To investigate whether the 6 compounds isolated from FS could interact with the endogenous ER signaling of MC3T3-E1 cells, we treated the rat cells with the compounds together with tamoxifen, inhibitor of ER pathway, and examined by ALP (Figure 3 A'-G'), and MTT assay (Figure 5) respectively. Compounds $1,3,4,16,17$ and 21 used in the above assay were all diluted into the concentration of 1.0 $\mu \mathrm{M}$ according to the results in Figure 2. As shown in Figure 3, compounds co-treated with tamoxifen (Figure 3, B'-G') compromise the ALP signal by compounds only groups (Figure 3, B-G). Consistently, all the chemicals would increase the OD value remarkably at $490 \mathrm{~nm}$, while decreased to the blank group level by in the tamoxifen added groups (Figure 5). From the two independent assays, the 6 compounds 
have the estrogen-like biological activities to promote proliferation and differentiation of MC3T3-E1 cells.

Results showed that, co-treatment with tamoxifen and compounds significantly decreased MC3T3E1 cells proliferation and differentiation comparing to exposure to compounds alone. These suggested that ER signaling influence the anti-osteoporosis properties of the compounds.

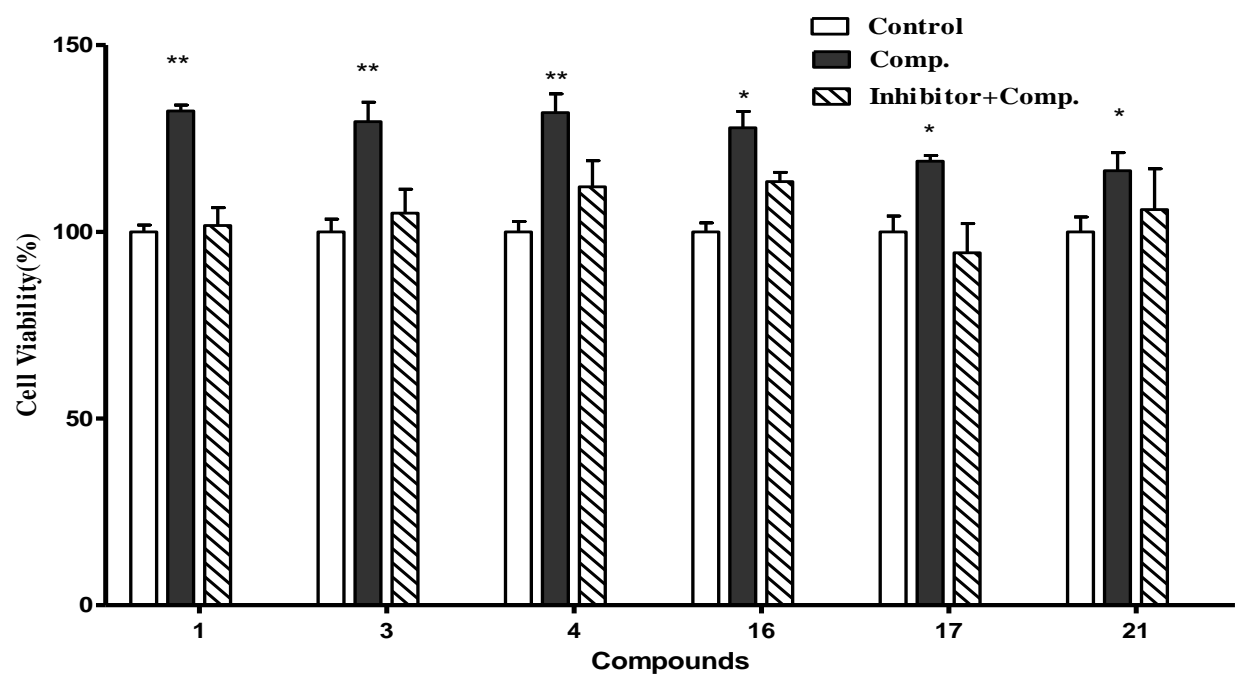

Figure 5. Effects of compounds with or without tamoxifen on MTT assay in MC3T3-E1cells. The groups with ALP and Alizarin red S signal positive (Compounds 1, 3, 4, 16, 17 and 21, at concentration of $1.0 \mu \mathrm{M}$ ) were verified by MTT assay. Different with assay in Figure 2, co-treatment with tamoxifen was also one group for each compound. Consistent with the results in Figure 2, the cell viability of these groups has remarkably increased, while decreased to the blank group level by in the tamoxifen added groups. Each assay was repeated for three times independently. $\left(* p<0.05,{ }^{*} p<0.01\right.$.).

\subsection{Compounds Could be Docked into the Active Pocket of ER Protein via Molecular Docking}

Molecular docking in the active pocket on $\operatorname{ER} \beta$ protein were performed to clarify the mode of compounds 1, 3, 4, 16, 17 and 21 interaction with ER, and to localize their accurate binding sites. As shown in Figure 6, all compounds bind to ER $\beta$ protein, some similar binding sites of the observed compounds were revealed. The binding amino acid residues, His475, Arg346, Leu339, Glu305 and Met336 were commonly shared between ligands and $\mathrm{ER} \beta$ protein. Compound $\mathbf{1}$ binds to ER $\beta$ by the A-ring phenol interacting with His-475 at the right, and the C-ring phenol interacting with hydrogen bond network of Glu-Arg- $\mathrm{H}_{2} \mathrm{O}$ triad at the left. Compounds 3, 16, 17 and 21 bind to $\mathrm{ER} \beta$ by the A-ring phenol interacting with Glu-Arg- $\mathrm{H}_{2} \mathrm{O}$ triad, and hydroxyl of the sugar ligand interact with His- 475 . Compound 4 binds to $\mathrm{ER} \beta$ by the sugar hydroxyl interacting with the Glu-Arg- $\mathrm{H}_{2} \mathrm{O}$ triad. The C-ring phenol of 4, 16, 17 and 21, interacting with the Leu 476.

Molecular docking by Schrödinger software showed that compounds 1, 3, 4, 16, 17 and 21 could form stable hydrogen bonds with the amino acid residues in the active pocket of $E R \beta$ respectively, which is consistent with in vitro experiments results. Hydroxy groups of the compounds could play an important role in achieving high binding affinities by interacting with the Glu-Arg-water triad (Glu305/Arg346) and His 475 in ER $\beta$. Above results indicated that one of the anti-osteoporosis mechanisms for these six compounds was by activating $\operatorname{ER} \beta$ receptor. 
1. Genistein<smiles>O=C1c2c(O)cc(O)cc2OCC1c1ccc(O)cc1</smiles>

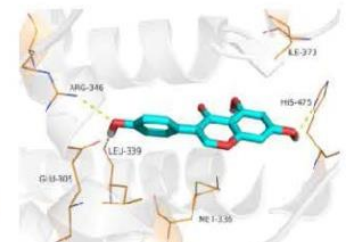

4. Sophorabioside

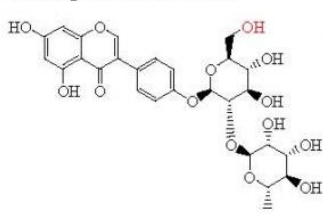

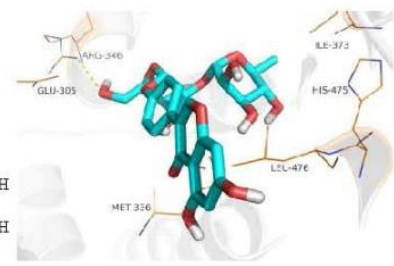

17. Nicotiflorin
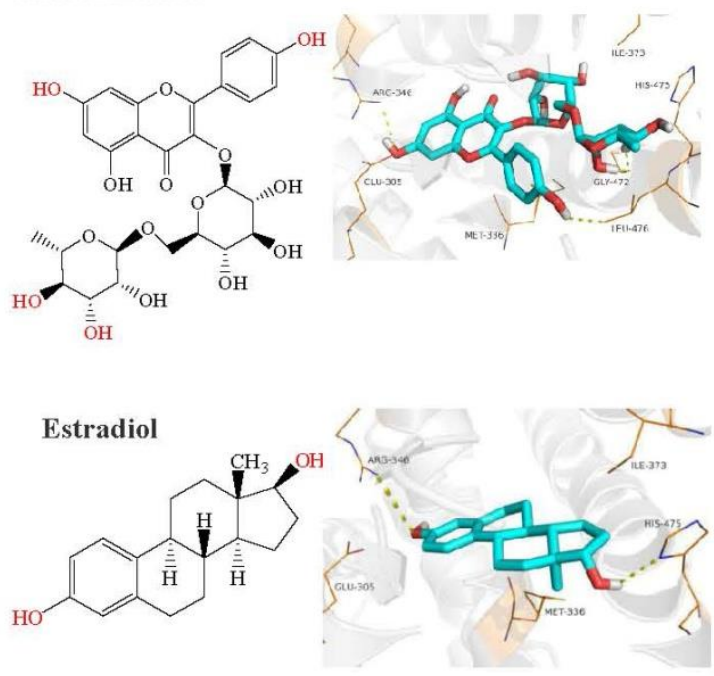

3. Sophoricoside

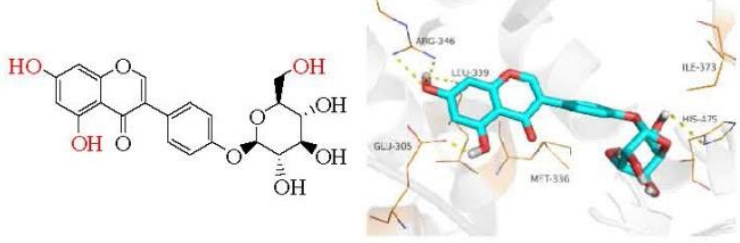

16. Sophoraflavonoloside
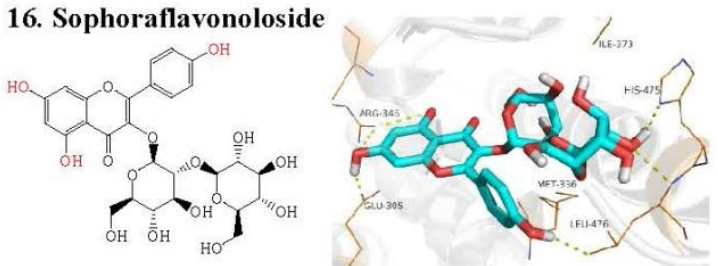

21. Rutin
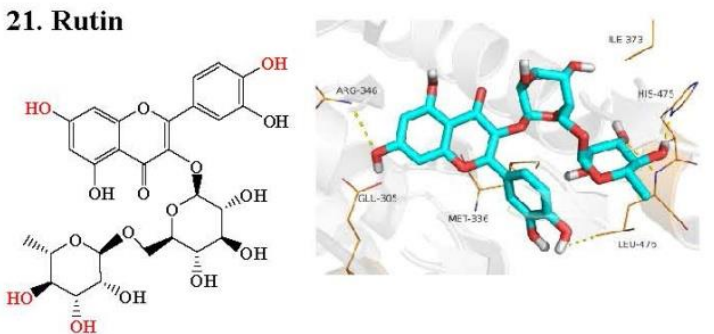

Figure 6. Interaction modes of compounds $1,3,4,16,17,21$ and estradiol within ER. The oxygen atems are colored red. Only key residues within 4A of ER are shown in stick representation. The yellow dotted lines show interactions.

Hormone replacement is considered to be a popular regime for osteoporosis prevention and treatment. However, recent evidence suggests that hormone used increases the risk of endometrial and breast cancers. Therefore, phytoestrogens therapy as an alternative treatment option is becoming more popular throughout the world [7]. Flavonoids with diverse structures, but most are similar to estrogen [28], is a natural product library of potential phytoestrogens. From our present study, these compounds are more prone to serve as potential chemopreventive agents in the therapy of osteoporosis, particularly in postmenopausal. Being used as food and medicine in China, FS is rich in flavonoids with estrogenlike effects, may be used as healthy supplementary in treating postmenopausal women osteoporosis.

\section{Acknowledgments}

This research was supported by Jilin University (Grant number 419080600013). Thank Cuizhu Wang, Zhenzhou Wang and Linxin Xiong for the method of molecular docking. Thank Yang Chen for helping in the in vitro activity experiments. Thank Professor Hui Xu for language editing and discussion for MTT and ALP staining assay. 


\section{Supporting Information}

Supporting information accompanies this paper on http://www.acgpubs.org/journal/records-ofnatural-products

\section{ORCID}

Yong Yang: 0000-0003-4115-0008

Yaping Tian: 0000-0001-9800-5026

Qinghe Zhang: 0000-0002-3261-7772

Xiaoqing Li: $\underline{0000-0001-6453-6005}$

Yun Fu: 0000-0001-8422-8149

Haotian Pei: 0000-0002-3550-3607

Dan Lui: 0000-0002-0311-5335

\section{References}

[1] R. Eastell and J.S. Walsh (2013). Is it time to combine osteoporosis therapies? Lancet 382, 5-7.

[2] R.M.H. Tei, C.H. Ramlau-Hansen, O. Plana-Ripoll, O. Brink, and B.L. Langdahl (2019). OFELIA: Prevalence of osteoporosis in fragility fract ure patients, Calcified Tissue Int., 104, 102-114.

[3] X. Lin, D. Xiong, Y.Q. Peng, Z.F. Sheng, X.Y. Wu, X.P. Wu, F. Wu, L.Q. Yuan and E. Y. Liao (2015). Epidemiology and management of osteoporosis in the People's Republic of China: current perspectives, Clin Interv Aging. 10, 1017-1033.

[4] F. Cosman (2018). Long-term treatment strategies for postmenopausal osteoporosis, Curr. Opin. Rheumatol. 30, 420-426.

[5] R.J. Santen, D.C. Allred, S.P. Ardoin, D.F. Archer, N. Boyd, G.D. Braunstein, H.G. Burger, G.A. Colditz, S.R. Davis, M. Gambacciani, B.A. Gower, V.W. Henderson, W.N. Jarjour, R.H. Karas, M. Kleerekoper, R.A. Lobo, J.E. Manson, J. Marsden, K.A. Martin, L. Martin, J.V. Pinkerton, D.R. Rubinow, H. Teede, D.M. Thiboutot, W.H. Utian and S. Endocrine (2010). Postmenopausal hormone therapy: an endocrine society scientific statement, J. Clin. Endocrinol. Metab. 95, s1-s66.

[6] K. Kerlikowske, A.J. Cook, D.S. Buist, S.R. Cummings, C. Vachon, P. Vacek and D.L. Miglioretti (2010). Breast cancer risk by breast density, menopause, and postmenopausal hormone therapy use, J. Clin. Oncol.. 28 (24), 3830-3837.

[7] A.F. Al-Anazi, V.F. Qureshi, K. Javaid and S. Qureshi (2011). Preventive effects of phytoestrogens against postmenopausal osteoporosis as compared to the available therapeutic choices: An overview, J. Nat. Sci. Biol. Med. 2, 154-163.

[8] M.L. Antonelli, A. Faberi, E. Pastorini, R. Samperi and A. Lagana (2005). Simultaneous quantitation of free and conjugated phytoestrogens in Leguminosae by liquid chromatography-tandem mass spectrometry, Talanta 66, 1025-1033.

[9] S.W. Fu, G.F. Zeng, S.H. Zong, Z.Y. Zhang, B. Zou, Y. Fang, L. Lu and D.Q. Xiao (2014). Systematic review and meta-analysis of the bone protective effect of phytoestrogens on osteoporosis in ovariectomized rats, Nutr. Res. 34, 467-477.

[10] J.E. Rossouw, G.L. Anderson, R.L. Prentice, A.Z. LaCroix, C. Kooperberg, M.L. Stefanick, R.D. Jackson, S.A. Beresford, B.V. Howard, K.C. Johnson, J.M. Kotchen and J. Ockene (2002). Writing Group for the Women's Health Initiative Investigators. Risks and benefits of estrogen plus progestin in healthy postmenopausal women: principal results from the Women's Health Initiative randomized controlled trial, JAMA. 288, 321-33.

[11] D. Smolinski, D. Wollner, J. Orlowski, J. Curcio, J. Nevels and L.S. Kim(2005). A pilot study to examine a combination botanical for the treatment of menopausal symptoms, J. Altern. Complement. Med. 11, 483489.

[12] J.G. Shim, S.H. Yeom, H.J. Kim, Y.W. Choi, D. I. Lee, K.Y. Song, S.H. Kwon and M.W. Lee (2005). Bone loss preventing effect of Sophorae Fructus on ovariectomized rats, Arch. Pharm. Res. 28, 106-110.

[13] H.M. Wei, T.J. Lan, Y.P. Lin and J.B. Wang (2011). To optimize the extraction process by orthogonal experiment and determination of the content of total flavonoids in Fructus Sophorae from different sources, Shannxi J. Tradit. Chin. Med. 32, 1231-1233.

[14] X.R. Zhi, Z.Y. Zhang, P.P. Jia, X.X.Zhang, L.Yuan, N. Sheng and L.T. Zhang (2015). Qualitative and quantitative determination of 15 main active constituents in Fructus Sophorae pill by liquid 
chromatography tandem mass spectrometry, Pharmacog. Mag. 11, 196-207.

[15] H.M. Wei and J.B. Wang (2010). The study in the development of the traditional chinese medicine Fructus Sophorae, Asia-Pacific Trad. Med. 6, 115-119.

[16] J.H. Wang, Y.P. Tang and F.C. Lou (2002). Studies on chemical constituents and pharmacological effects of Furctus Sophorae, World Phytomed. 17, 58-60.

[17] Z.L. Wang, J.Y. Sun, D.N. Wang, Y.H. Xie, S.W. Wang and W.M. Zhao (2006). Pharmacological studies of the large-scaled purified genistein from Huaijiao (Sophora japonica-Leguminosae) on anti-osteoporosis, Phytomedicine 13, 718-723.

[18] H.M. Abdallah, A.M. Al-Abd, G.F. Asaad, A.B. Abdel-Naim and A.M. El-halawany (2014). Isolation of antiosteoporotic compounds from seeds of Sophora japonica. PLoS One 9, p. e98559.

[19] J.P. Bilezikian(2002). Sex steroids, mice, and men: when androgens and estrogens get very close to each other, J. Bone Miner. Res.17, 563-566.

[20] L. Cao, R. Bu, J.I. Oakley, S.E. Kalla and H.C. Blair (2003). Estrogen receptor-beta modulates synthesis of bone matrix proteins in human osteoblast-like MG63 cells, J. Cell Biochem. 89, 152-164.

[21] C. Yang, M. Zhang, Y. Li, Y. Wang, W. Mao, Y. Gao and H. Xu (2015). Streptozotocin aggravated osteopathology and insulin induced osteogenesis through co-treatment with fluoride, Biol. Trace Elem. Res. 168, 453-461.

[22] J. Yang, J. Zhang, C. Ding, D. Dong and P. Shang (2018). Regulation of osteoblast differentiation and iron content in MC3T3-E1 cells by static magnetic field with different intensities, Biol. Trace Elem. Res. 184, 214-225.

[23] Y.S. Kim, K.C. Choi and K.A. Hwang (2015). Genistein suppressed epithelial-mesenchymal transition and migration efficacies of BG-1 ovarian cancer cells activated by estrogenic chemicals via estrogen receptor pathway and downregulation of TGF-beta signaling pathway, Phytomedicine 22, 993-999.

[24] Y.X. Wang, M. Li, H.Q. Zhang, M.X. Tang, C.F. Guo, A. Deng, Y. Chen and L.G. Xiao (2016). Opposite function of ER alpha and ER beta in cControlling 17 beta-estradiol-mediated osteogenesis in osteoblasts, Arch. Med. Res. 47, 255-261.

[25] X. Li, B. Peng, X. Zhu, P. Wang, Y. Xiong, H. Liu, K. Sun, H. Wang, L. Ou, Z. Wu, X. Liu, H. He, S. Mo, X. Peng, Y. Tian, R. Zhang and L. Yang (2017). Changes in related circular RNAs following ER beta knockdown and the relationship to rBMSC osteogenesis, Biochem. Biophys. Res. Commun. 493, 100-107.

[26] C. Yang, Y. Wang and H. Xu(2017). Fluoride regulate osteoblastic transforming growth factor-beta 1 signaling by mediating recycling of the type I receptor ALK5, PLoS One 12, p. e0170674.

[27] R.M. Sterner, K.N. Kremer, A. Dudakovic, J.J. Westendorf, A.J. van Wijnen and K.E. Hedin (2018). Tissuenonspecific alkaline phosphatase is required for MC3T3 osteoblast-mediated protection of acute myeloid leukemia cells from Apoptosis, J. Immunol. 201, 1086-1096.

[28] D. Guo, J. Wang, X. Wang, H. Luo, H. Zhang, D. Cao, L. Chen and N. Huang (2011). Double directional adjusting estrogenic effect of naringin from Rhizoma drynariae (Gusuibu), J. Ethnopharmacol. 138, 451457.

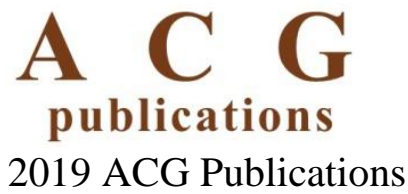

